\title{
THE TRANSPORT AND EXCRETION OF URIC ACID IN MAN. II. THE ENDOGENOUS URIC ACID-LIKE CHROMOGEN OF BIOLOGICAL FLUIDS
}

\author{
By W. Q. WOLFSON, B. HUDDLESTUN, ANd R. LEVINE
}

(From the Department of Metabolism and Endocrinology, ${ }^{1}$ Michael Reese Hospital, Chicago, Illinois)

(Received for publication March 24, 1947)

Within recent years, enzymatic methods for the determination of true urate have become available. The introduction of such methods by Blauch and Koch $(1,2)$ has made it possible to estimate true urate in biological material with a high degree of accuracy ( 3 to 10$)$.

All uricase methods involve the colorimetric determination of uric acid on two aliquots of a sample, one of which has been treated with uricase to destroy the true uric acid present. The apparent concentration of uric acid in the untreated sample, as determined colorimetrically, is referred to as "total urate"; and the concentration remaining after treatment with uricase is referred to as the "urate-like chromogen" (or briefly, "chromogen"). By substracting the concentration of chromogen from that of total urate, the concentration of "true urate" destroyed by the enzyme is obtained.

Most authors have tacitly assumed that the chromogen was merely an interference with the maximal accuracy of urate determination, but the results we obtained appear to require another explanation. A preliminary report on some of this data has appeared elsewhere (11) and this paper is chiefly concerned with the results of our investigations dealing with the chemical nature and physiological significance of the urate-like chromogen.

\section{METHODS}

Total urate, true urate, and chromogen are estimated by our modification of the method of Buchanan, Block, and Christman (3) for the Evelyn photoelectric colorimeter. Details of other chemical and physiological methods and complete data on our normal human subjects and gout patients summarized below will appear in a later publication (12).

Urate solutions for continuous intravenous injection in normal human subjects were prepared by dissolving uric

1 The department is in part supported by the Michael Reese Research Foundation. acid in $0.05 \mathrm{~N}$ sodium hydroxide. The solutions were neutralized and sterilized by Berkfeld filtration. Only a few such experiments were performed as we, like a number of previous workers, have found these solutions to produce frequently unpleasant reactions, chiefly nausea and vomiting. These reactions could not be ascribed to any possible decomposition products since 100 per cent of the added urate was recoverable as true urate by analysis, even after standing for 1 to 2 days. Nucleic acid was given orally in 1.0-gram gelatin capsules; doses as high as 20 grams appear to be fairly well tolerated. Below 10 grams, there are no untoward effects; but single doses in the 10 - to 20 -gram range may cause transient malaise, hypotension, and vasodilation in the second hour, presumably attributable to adenosine. Other solutions of purines used in animal experiments were made up in .05 $\mathrm{N} \mathrm{NaOH}$.

All determinations were done on plasma or serum rather than on whole blood. Although the Folin uric acid precipitation is supposed to be an "unlaked blood" method (i.e. the red cells are precipitated without hemolysis) this is not true (13). In addition, the red cells contain a large amount of ergothionine which gives considerable urate color.

TABLE I

Effect of fasting on plasma total urate, chromogen and true urate concentrations in normal human subjects and in dogs

\begin{tabular}{l|c|c|c|c}
\hline & $\begin{array}{c}\text { Total } \\
\text { urate }\end{array}$ & $\begin{array}{c}\text { Chromo- } \\
\text { gen }\end{array}$ & $\begin{array}{c}\text { True } \\
\text { urate }\end{array}$ \\
\hline & $\begin{array}{c}\text { mgm. per } \\
100 \mathrm{ml} .\end{array}$ & $\begin{array}{c}m g m . \text { per } \\
100 \mathrm{ml} .\end{array}$ & $\begin{array}{c}\text { mgm. per } \\
100 \mathrm{ml} .\end{array}$ \\
\hline
\end{tabular}

Human subjects

\begin{tabular}{|c|c|c|c|}
\hline $\begin{array}{l}\text { HBW, } 1 \text { hour post-prandial } \\
\text { HBW, } 24 \text { hours fasting }\end{array}$ & $\begin{array}{l}4.0 \\
4.7\end{array}$ & $\begin{array}{l}0.6 \\
0.6\end{array}$ & $\begin{array}{l}3.4 \\
4.1\end{array}$ \\
\hline $\begin{array}{l}\text { WQW, } 1 \text { hour post-prandial } \\
\text { WQW, } 24 \text { hours fasting }\end{array}$ & $\begin{array}{l}6.4 \\
6.6\end{array}$ & $\begin{array}{l}0.7 \\
0.7\end{array}$ & $\begin{array}{l}5.7 \\
5.9\end{array}$ \\
\hline \multicolumn{4}{|c|}{ Dogs } \\
\hline $\begin{array}{l}\text { Dog 2, postabsorptive } \\
\text { Dog 2, } 3 \text { days fasting }\end{array}$ & $\begin{array}{l}1.1 \\
1.1\end{array}$ & $\begin{array}{l}0.4 \\
0.7\end{array}$ & $\begin{array}{l}0.7 \\
0.4\end{array}$ \\
\hline $\begin{array}{l}\text { Dog } 230, \text { postabsorptive } \\
\text { Dog } 230,3 \text { days fasting }\end{array}$ & $\begin{array}{l}0.9 \\
1.1\end{array}$ & $\begin{array}{l}0.5 \\
0.5\end{array}$ & $\begin{array}{l}0.4 \\
0.6\end{array}$ \\
\hline
\end{tabular}




\section{RESULTS}

The endogenous origin of chromogen. Table I shows the effect of fasting upon the plasma concentrations of chromogen in man and in the dog. These results, which show that chromogen concentrations do not decline upon fasting, indicate the endogenous origin of this substance or group of substances.

The known urate chromogens. A large number of substances (Table II) are not attacked by uricase but do give color in the uric acid reaction. It is, however, possible to conclude that most of these substances cannot be responsible for the observed plasma concentrations of chromogen.

The non-purine substances with large chromogenic equivalents (ascorbate, resorcinol, cystine, glutathione, and ergothionine) are not present

TABLE II*

Ability of certain substances to produce color with the uric acid reagents, with known chromogenic equivalents

Substances which give color
1-methyluric acid $\neq$
Uric acidł
1,3-dimethyluric acid
Ascorbic acid §
Resorcinol
3-methyluric acid
Ergothionineł
Uric acid-9-riboside
1,7-dimethyluric acid
Cystine
Glutathione
3,7-dimethyluric acid
1,3,7-trimethyluric acid
7-methyluric acid
6-amino-2,8-dihydroxy-purine

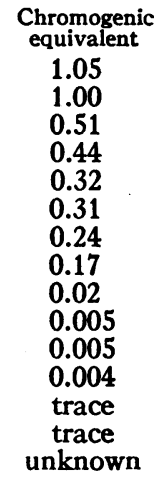

Substances which do not give color

Adenine

Guanine

Xanthine

Hypoxanthine

Methylxanthines

Oxyacetylene-diurein-

carboxylic acid

- Data chiefly from Buchanan, Block and Christman $(3,4)$, Booth (29), and Falconer and Gulland (30). We have confirmed the chromogenic equivalents for the methyluric acids and for resorcinol reported by Buchanan, Block and Christman $(3,4)$. From the observation that uricase action upon uric acid gives rise only to nonchromogenic products, it is inferred that oxyacetylenediurein-carboxylic acid, the chief reaction product (31), is non-chromogenic.

t The chromogenic equivalent is the number of milligrams of uric acid required to give a color equal in intensity to that produced by 1.0 milligram of the substance being tested.

$\ddagger$ Precipitated by silver reagents.

When ascorbic acid is added to plasma samples treated routinely with no special precautions to prevent oxidation, the chromogenic equivalent is approximately $\mathbf{0 . 2 0}$. either in plasma or urine in concentrations large enough to account for the amounts of chromogen present. (See Table II.) In addition, the data of Buchanan, Block and Christman $(3,4)$ appear to indicate that the endogenous chromogen is not precipitated by their silver reagent which precipitates ergothionine quantitatively.

On the other hand, the methylxanthines of dietary beverages (theophylline, theobromine, caffeine), when oxidized in intermediary metabolism, give rise to methylurates of considerable chromogenic value $(4,14)$. Coffee, tea, and chocolate, however, can hardly account for the plasma and urine chromogens in the animal, in the fasting human, or in subjects on a purine-free diet.

One substance may deserve more study than it has yet received. Some years ago, Minkowski and other workers $(15,16)$ found that when large amounts of adenine were fed to animals, a purine derivative was deposited in the cells of the renal tubule. Raska (17) has recently made a similar observation. Upon analysis, this purine proved to be 6-amino-2,8-dihydroxy-purine. It is known to give color with the uric acid reagents and its precursor, oxyadenine (6-amino-2-oxy-purine), has been found in pig blood (18). We are aware of no studies indicating either its occurrence or absence in human intermediary metabolism.

It is apparent that if the endogenous chromogen is of purine origin, as we shall attempt to show, it must be very similar to uric acid in order to give appreciable color. The minimum criteria appear to be the presence of 2 oxygen atoms in the 2,6 , and 8 positions with another radical in the third position or 3 oxygen atoms in these loci. Most of the substituted uric acid derivatives, however, give considerably less color than urate itself. The breakdown products of uric acid are not chromogenic, and precursors as similar as the dihydroxypurines also are not chromogenic.

Since it is possible on these most elementary chemical considerations tentatively to eliminate most known urate derivatives, the endogenous chromogen appears to be a substance the composition of which is as yet not known.

Occurrence and distribution of chromogen. In Table III we have summarized a large body of data concerning the values for true urate and chromogen in various biological fluids (19). It is ap- 
TABLE II

Urate partition in certain biological fuids*

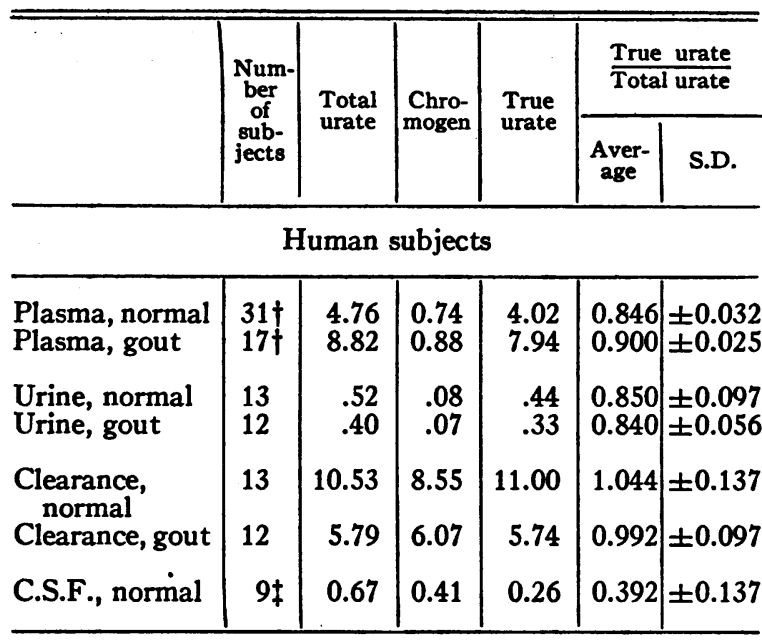

Dogs

\begin{tabular}{l|l|l|l|l|l|l}
\hline Plasma, normal & 9 & 1.03 & 0.60 & 0.43 & 0.419 & \pm 0.164 \\
\hline
\end{tabular}

* Plasma and C.S.F. values are milligrams per $100 \mathrm{ml}$. Urine values are milligrams per minute per $1.73 \mathrm{sq} . \mathrm{m}$. Clearance values are ml. of plasma cleared per minute per 1.73 sq. $\mathrm{m}$.

† Average plasma values were obtained on larger groups of subjects, Both normal and gouty, than were urine and clearance values. Urine and clearance results quoted were obtained simultaneously and in the same individuals.

¥ The data for normal C.S.F. are those for pooled normal fluids (10).

parent that the chief constituent of the total urate values in human plasma and urine, both in normals and in persons with gout, is true urate. In fact, the proportion of total urate formed by true urate is so regular that it may safely be estimated by a conversion factor. Similarly, there is little difference between the total urate and true urate clearance, a point of importance when considering the results of earlier investigation.

The clearance of chromogen is similar in magnitude to that of true urate, and is reduced in gout as is that of true urate, observations which again point to its resemblance to uric acid and certainly suggest it to be a purine derivative.

However, in normal human cerebrospinal fluid (10) and in dog plasma (19), the situation is somewhat different. Here, chromogen forms over 50 per cent of total urate values, and the ratio of true urate to total urate is sufficiently irregular so that it appears hazardous to employ a conversion factor.
Observations on ultrafiltrates of human plasma ([10], Table III) show considerably less plasma binding of chromogen than of true urate, when cellophane ultrafiltration is used as the criterion of binding. Moreover, the C.S.F./plasma ratio for chromogen is considerably greater than for true urate ([10], Table I).

We have been fortunate enough to observe a patient with chronic monoblastic leukemia and gout who had an output of urate of $2.95 \mathrm{mgm}$. per minute or about 6 times normal. In this patient, both true urate and chromogen were excreted in increased amounts, the chromogen excretion being about 4 times normal.

Site of origin of chromogen. In the dog, rabbit, and monkey, removal of the liver (or evisceration), is followed by a rise in plasma uric acid owing to the removal of hepatic uricase which normally converts uric acid to allantoin (20 to 24). If the renal pedicles are ligated, or the kidneys removed, excretion of urate and allantoin is prevented, making it possible to study the peripheral production of urate by observation of the plasma uric acid level. In this eviscerated-bilaterallynephrectomized preparation, the rise in plasma urate, at least for the first few hours postoperatively, is linear, indicating that, either reduction of urate to its precursors is not affected by rising plasma levels or that breakdown rates and resynthesis rates are so balanced as to mask this effect.

In the eviscerated-bilaterally-nephrectomized dog (Table IV), operation is followed by a rise in both true urate and chromogen. This appears actually to depend upon the rate at which urate precursors are made available, since the injection

TABLE IV

Effect of evisceration and bilateral nephrectomy upon plasma urate partition in the dog

The data are average results of 5 experiments.

\begin{tabular}{|c|c|c|c|c|}
\hline & $\begin{array}{l}\text { Total } \\
\text { urate }\end{array}$ & $\underset{\text { gen }}{\text { Chromo- }}$ & $\begin{array}{l}\text { True } \\
\text { urate }\end{array}$ & $\frac{\text { True urate }}{\text { Total urate }}$ \\
\hline Preoperative & $\begin{array}{c}\text { mgm. per } \\
100 \text { ml. } \\
0.90\end{array}$ & $\begin{array}{c}\text { mgm. per } \\
100 \text { ml. } \\
0.60\end{array}$ & $\begin{array}{c}\text { mgm. per } \\
100 \mathrm{ml} . \\
0.30\end{array}$ & $\begin{array}{c}0.33 \\
0.3\end{array}$ \\
\hline $\begin{array}{c}\text { Postoperative } \\
0.0 \text { hour } \\
1.5 \text { hours } \\
3.0 \text { hours }\end{array}$ & $\begin{array}{l}1.53 \\
3.00 \\
4.33\end{array}$ & $\begin{array}{l}0.70 \\
1.03 \\
1.23\end{array}$ & $\begin{array}{l}0.83 \\
1.97 \\
3.10\end{array}$ & $\begin{array}{l}0.54 \\
0.66 \\
0.72\end{array}$ \\
\hline
\end{tabular}




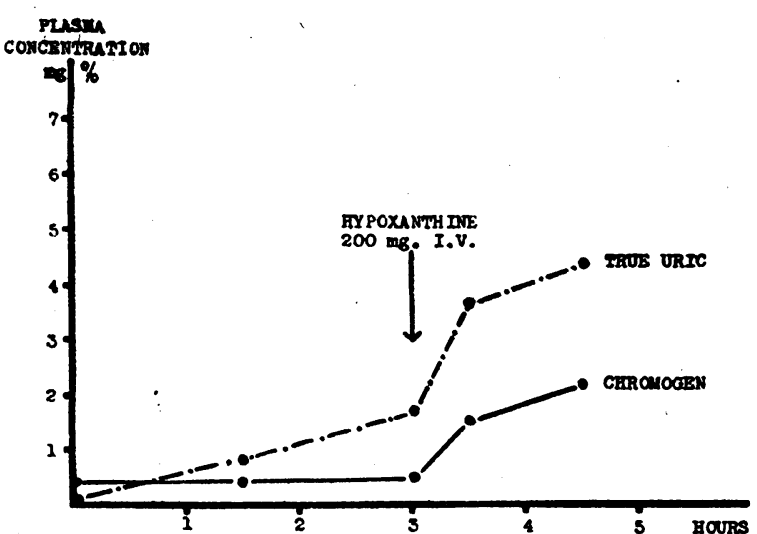

Fig. 1. Efrect of Hypoxanthine InJected IntraveNOUSLY IN HePATECTOMIZED Dog

of xanthine or hypoxanthine (Figure 1) into this preparation is followed by a rapid, simultaneous rise in both plasma true urate and plasma chromogen. However, while these data indicate that chromogen may be formed in the peripheral tissue, they do not exclude the possibility that it is derived from urate.

Effect of urate and its precursors in man. In man, the oral administration of large doses of nucleic acid (Figure 3 ) leads to increased excretion of both true urate and chromogen. Freyberg, Block and Geib (25) have shown that administration of adenine or guanine has similar effects.

Man, however, is particularly suitable for the study of the possibility that chromogen may be formed from urate in the peripheral tissue since

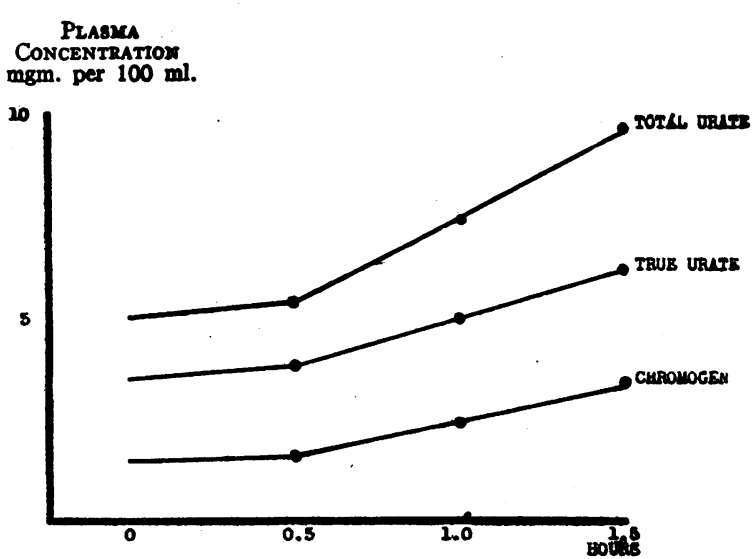

Fig. 2. Emfect of Continuous Intravenous Infusion of Sodium URATe in Human

One-half gram of sodium urate solution, $100 \mathrm{mgm}$. per $100 \mathrm{ml}$., was injected between 0.5 and 1.5 hours. he lacks the hepatic uricase of the dog. The results of this experiment (Figure 2) showed that the continuous intravenous injection of urate solutions leads to a rapid rise in both plasma true urate and chromogen. Since it is possible to recover 100 per cent of urate added to plasma or blood in vitro, one must conclude that some system, presumably enzymatic, located in the peripheral tissue, or located in the blood and very susceptible to spontaneous breakdown, is responsible.

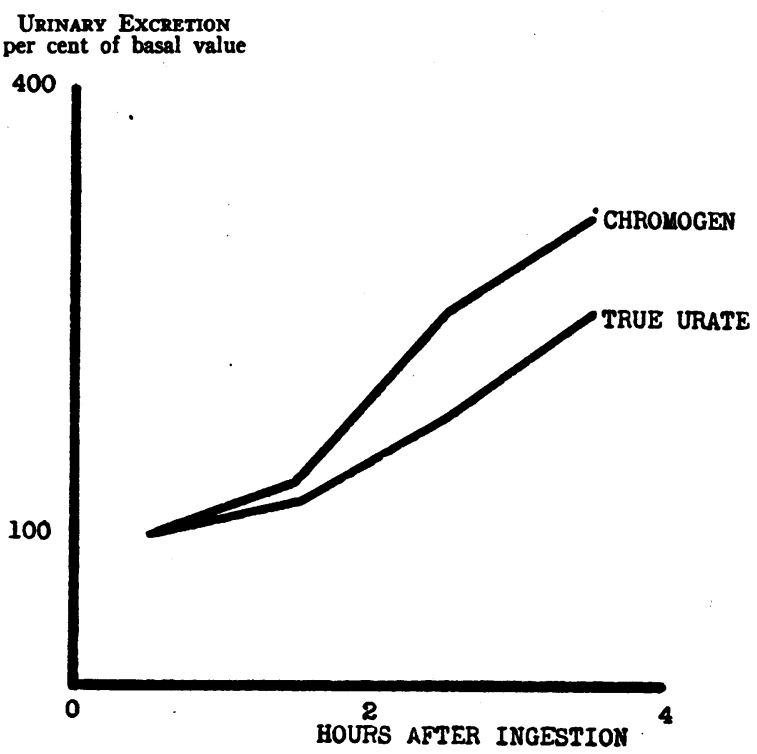

Fig. 3. Effect of a Single 15.0-Gram Oral Dose of Nucleic ACID UPON THE URINary Excretion of TrUE URATE AND OF ChROMOgeN

Effect of uricosuric drugs on chromogen excretion. Another similarity between urate and chromogen lies in the response to the uricosuric group of drugs, those agents which increase urate output in urine and decrease its plasma level. All the uricosuric drugs so far investigated (cincophen,

TABLE V

Effect of diodrast upon urine urate partition in a normal human subject

Ten ml. of , 35 per cent diodrast were injected intravenously at the end of the first hour, and at the end of the second hour.

\begin{tabular}{c|c|c|c}
\hline \hline Hour & Total urate & Chromogen & True urate \\
\cline { 2 - 3 } & mgm. per min. & mgm. per min. & mgm. per mix. \\
1 & 0.64 & 0.13 & 0.51 \\
2 & 2.66 & 0.31 & 2.35 \\
3 & 2.09 & 0.20 & 1.89 \\
4 & 1.07 & 0.18 & 0.89 \\
\hline
\end{tabular}


salicylate, diodrast) have been found to increase the output of chromogen as well as that of true urate (26). The results of a typical experiment with diodrast are shown in Table V.

The chromogen content of a gouty tophus. Because of the many similarities in the physiological behavior of true urate and chromogen, we were interested to see whether chromogen, like true urate, is deposited in the gouty tophus.

A large surgically removed tophus was made available for analysis. ${ }^{2}$ This analysis (Table VI) was distinctly surprising in that it showed the virtual absence of chromogen.

TABLE VI Analysis of surgically removed tophus

$\begin{array}{lc}\text { Weight of sample } & \text { grams } \\ \text { Water } & 5.500 \\ \text { Connective tissue } & 3.100 \\ \text { Total urate } & 1.000 \\ \text { Chromogen } & 0.681 \\ \text { True urate } & \text { Negligible } \\ \text { Cholesterol } & 0.681 \\ \text { Calcium } & 0.055 \\ & 0.007 \\ \text { Patient's plasma on day } & \text { mgm. per } 100 \mathrm{ml} . \\ \text { preceding operation: } & \\ \text { Total urate } & \\ \text { Chromogen } & 7.3 \\ \text { True urate } & 0.7 \\ & 6.6\end{array}$

Apart from its physiological importance as differentiating the behavior of true urate and endogenous chromogen, this finding appears possibly to have practical significance in the management of gout. Ordinarily, coffee, tea, and chocolate are forbidden to the gout patient because it is commonly supposed that they may give rise to uric acid and so increase tophaceous deposits. Actually, the methylxanthines of these beverages are metabolized to methylurates $(3,4,14)$; these substances are not attacked by uricase and are therefore chromogens. Since, apparently, no chromogenic substance is deposited in the gouty tophus, it is obvious that the methylurates of exogenous origin do not contribute to tophus formation, and need not be eliminated from the diet on this account.

\section{DISCUSSION}

We may now briefly summarize our present data on the endogenous uric acid-like chromogen. This substance (or substances) is shown to be

\footnotetext{
2 Through the kindness of Dr. E. F. Rosenberg.
}

endogenous in origin since its plasma concentration and urine output are not markedly diminished by fasting. It originates spontaneously with urate in the peripheral tissue of the $\operatorname{dog}$ and may be formed from xanthine or hypoxanthine by the peripheral tissue of the dog. In man, who lacks uricase and appears to be comparable to the hepatectomized dog, chromogen is also formed from ingested urate precursors, as is true urate. However, injected urate also leads to chromogen production so rapidly as to suggest an enzymatic conversion. The data permit no conclusion as to whether the conversion of endogenous chromogen to urate is reversible physiologically; although it is clear that neither conversion occurs in vitro.

Data on a patient with leukemia and gout indicate that when urate is overproduced, chromogen is also overproduced. The chromogen clearance is of the same order of magnitude as the true urate clearance in man; and both are decreased in gout. Furthermore, the uricosuric drugs which increase urate excretion also increase chromogen excretion.

Thus, there are many resemblances between the behavior of true urate and of chromogen, but there also are some differences. Unlike true urate, chromogen is not attacked by uricase. It appears to be somewhat more freely ultrafiltrable from plasma through cellophane than is true urate ([10], Table III). It is not deposited in the gouty tophus (Table VI). There is a suggestion that, unlike urate, it is not precipitated by silver reagents (4). A critical survey of the known purine derivatives which might satisfy these criteria reveals that none appears to be satisfactory. A possible exception is 6-amino-2-8-dihydroxypurine, but so little is known of the physiology of this substance that a decision as to its importance cannot be reached.

In 1939, Ball (27) reported that the endproduct obtained when purified xanthine oxidase acted upon hypoxanthine was a substance not attacked by purified uricase, in spite of the fact that the oxygen consumption was that predicted for uric acid formation. If either crude xanthine oxidase or crude uricase were substituted for the pure enzyme in this experimental system, the reaction continued to completion.

The work of Ball is reminiscent of the much older suggestion of Gudzent (see 13) that both 
the lactam and lactim tautomers of uric acid might be stable enough to coexist in biological fluids under certain circumstances. It is true that Ball's experiment required extremely precise conditions and, while this is undeniably an objection, it does indicate that in a suitable biological system in vitro, there may be a tautomer of uric acid which is not attacked by uricase. Guanase may possibly have such a selective action; this was suggested by the finding that it attacks the methylated derivatives only of the lactam tautomer of guanine (28). A more pertinent objection to identifying Ball's substance with our endogenous chromogen lies in the fact that our chromogen is not attacked by the uricase we use, which is a crude, defatted, kidney extract. At present, our feeling is that the chromogen is more likely to be a tautomer of urate than a substance such as 6-amino-2,8-dihydroxy-purine; but this is based solely on an impression that the amino substitution is unlikely from our present knowledge of the behavior of urate in the body.

Two findings appear to be of practical clinical importance. The observation that a gouty tophus contains only true urate and no chromogen, endogenous or exogenous, when considered in the light of our present knowledge that dietary methylxanthines give rise to methylurates and not to uric acid, appears possibly to indicate that the patient with gout need no longer be penalized by having coffee, tea and chocolate removed from his diet. So far as accelerating the rate of tophus deposition, these beverages appear innocuous.

The other, probably more important, conclusion bears upon the moot question of the reliability of the colorimetric estimation of urate. Our data show quite clearly that the relation between true urate and total urate in normal and gouty plasma and urine is so uniform that, if desired, true urate may be estimated from total urate values by a conversion factor. In addition, a large body of urate clearance data obtained by various investigators before the introduction of the uricase method has been shown to be almost as accurate as if true urate clearances had been studied, since the total urate clearance is almost exactly equal to the true urate clearance.

There is no question that one should use true urate determinations for maximal physiological precision, or when studying material other than human plasma and urine. However, when an estimate of the quantitative rate of nucleoprotein breakdown or turnover is desired, total urate determination appears to give a more complete picture. The chromogens discarded in the true urate determination appear to be as much a part of nucleoprotein metabolism as is true urate and, in fact, may arise from urate in the body. Only under unusual conditions, such as the ingestion of massive doses of caffeine, does the colorimetric determination on human plasma and urine become inaccurate. In contrast, the colorimetric determination of urate in human plasma or urine appears to be an entirely satisfactory method for clinical use and rather gains, than loses, in value because of a slight degree of non-specificity.

\section{SUM MARY}

Biological fluids contain material which gives the arsenophosphotungstate reaction for urate but which is not attacked by uricase. A portion of these chromogenic substances appears to be purine in nature and endogenous in origin. In many ways this endogenous uric acid-like chromogen resembles true uric acid, but it also has several differences in behavior.

The chromogen is known to be endogenous in origin since neither its plasma concentration nor urinary output is markedly affected by fasting. Unlike urate, it is not precipitated by silver, and it is somewhat more diffusible through cellophane and through the blood-brain barrier than is true urate. Increased urate production due to leukemia or induced by the feeding or injection of urate precursors leads to increases in chromogen production. This also occurs, however, when urate is injected intravenously. The chromogen clearance is of the same order of magnitude as the true urate clearance, and is similarly reduced in gout. Uricosuric drugs increase the chromogen excretion as well as true urate excretion.

For ordinary clinical pathological studies, the colorimetric determination of urate in plasma and urine, including both true urate and chromogen, appears to give a better picture of the overall rate of purine turnover than does the uricase determination. Moreover, the true urate to total urate ratio in human plasma and urine is sufficiently constant so that true urate may be reliably estimated from total urate. The true urate clearance does not differ appreciably from the total urate clearance. However, in human cerebro- 
spinal fluid and in dog plasma, true urate may not be estimated from total urate.

Study of the endogenous urate-like chromogen has thrown little light on the pathological physiology of gout. It does appear, however, that since only true uric acid is deposited in the gouty tophus, there may be little reason to withhold coffee, tea, or chocolate from the diet of the patient with gout since the methylxanthines of these beverages do not give rise to true urate.

\section{ACKNOWLEDGMENT}

Dr. H. Dunham Hunt of Saratoga Springs, New York, has collaborated with us in the clinical studies summarized. Dr. Victor C. Myers of Western Reserve University School of Medicine was kind enough to supply us with generous samples of several methyluric acids from his collection. The data on the patient with leukemia and gout were obtained through the cooperation of Dr. Rafael Isaacs of the Department of Hematology, Michael Reese Hospital.

Schwarz Laboratories of New York City, N. Y., made available the supplies of purified nucleic acid used in our human experiments, and other purines used in these studies. Cellophane membranes used in ultrafiltration studies were obtained through the cooperation of E. I. du Pont de Nemours Company.

\section{BIBLIOGRAPHY}

1. Blauch, M. B., and Koch, F. C., A new method for the determination of uric acid in blood with uricase. J. Biol. Chem., 1939, 130, 443.

2. Blauch, M. B., and Koch, F. C., Application of the uricase method to the study of changes in vitro in the uric acid content of certain mammalian bloods. J. Biol. Chem. 1939, 130, 455.

3. Buchanan, O. H., Block, W. D., and Christman, A. A., The metabolism of the methylated purines. I. The enzymatic determination of urinary uric acid. J. Biol. Chem., 1945, 157, 181.

4. Buchanan, O. H., Christman, A. A., and Block, W. D., The metabolism of the methylated purines. II. Uric acid excretion following the ingestion of caffeine, theophylline and theobromine. J. Biol. Chem., 1945, 157, 189.

5. Bulger, H. A., and Johns, H. E., The determination of plasma uric acid. J. Biol. Chem., 1941, 140, 427.

6. Mull, J. W., Determination of uric acid in whole blood and serum. J. Lab. \& Clin. Med., 1943, 28, 1038.

7. Schaffer, N. K., Dill, L. V., and Stander, H. J., The effect of renin on the uric acid metabolism of the pregnant and non-pregnant Dalmatian dog. Endocrinology, 1941, 29, 243.

8. Schaffer, N. K., and Stander, H. J., True uric acid in the hyperuricemia of pre-eclampsia and eclampsia. Proc. Soc. Exper. Biol. \& Med., 1940, 45, 180.

9. Schaffer, N. K., The determination of uric acid in urine with crude uricase. J. Biol. Chem., 1944, 153, 163.
10. Wolfson, W. Q., Levine, R., and Tinsley, M., Transport and excretion of uric acid in man: I. True uric acid in normal cerebrospinal fluid, in plasma, and in ultrafiltrates of plasma. J. Clin. Invest., 26, 991.

11. Levine, R., Wolfson, W. Q., and Huddlestun, B., A purine metabolite in plasma which gives the same color reaction as uric acid. Proc. Am. Fed. Clin. Res., 1945, 2, 56.

12. In preparation.

13. Peters, J. P., and Van Slyke, D. D., Quantitative Clinical Chemistry, Vol. I. Interpretations. The Williams and Wilkins Company, Baltimore, 1946, 2nd edition, Table 24, p. 635.

14. Myers, V. C., and Hanzal, R. F., The metabolism of methylxanthines and their related methyluric acids. J. Biol. Chem., 1946, 162, 309.

15. Minkowski, O. Gicht in Neue Deutsche Klinik. Berlin, Urban and Schwarzenberg 1930, 4, 183.

16. Ebstein, W., and Bendix, E., Ueber das Schicksal der in die Blutbahn gebrachten Purinkörper. Arch. $f$. path. anat. u. physiol., 1904, 178, 464.

17. Raska, S., Personal communication.

18. Buell, M. V., and Perkins, M. E., Oxyadenine. J. Biol. Chem., 1927, 72, 745.

19. Unpublished results.

20. Bollman, J. L., Mann, F. C., and Magath, T. B., Studies on the physiology of the liver. VIII. Effect of total removal of the liver on the formation of urea. Am. J. Physiol., 1924, 69, 371.

21. Bollman, J. L., Mann, F. C., and Magath, T. B., Studies on the physiology of the liver. X. Uric acid following total removal of the liver. Am. J. Physiol., 1925, 72, 629.

22. Bollman, J. L., and Mann, F. C., Studies on the physiology of the liver. XXV. Allantoin and uric acid following total removal of the liver. Am. J. Physiol., 1933, 104, 242.

23. Maddock, S., and Svedberg, A., The effect of the total removal of the liver of the monkey. Am. J. Physiol., 1938, 121, 203.

24. Svedberg, A., Maddock, S., and Drury, D. D., The effect of the total removal of the liver in the rabbit. Am. J. Physiol., 1938, 121, 209.

25. Freyberg, R. H., Block, W. D., and Geib, N., Uric acid metabolism studies in gout. J. Clin. Invest., 1944, 23, 933.

26. Robinson, W. D., and Block, W. D., The effect of salicylates on the blood concentration and urinary excretion of urates and non-urate chromogens. Proc. Cen. Soc. Clin. Res., 1946, 19, 69.

27. Ball, E. G., Xanthine oxidase: purification and properties. J. Biol. Chem., 1939, 128, 51.

28. Hitchings, G. H., and Falco, E. A., The identification of guanine in extracts of girella nigricans. The specificity of guanase. Proc. Nat. Acad. Sci., 1944, 30, 294.

29. Booth, V. H., The specificity of xanthine oxidase. Biochem. J., 1938, 32, 494.

30. Falconer, R., and Gulland, J. M., Uric acid riboside. J. Chem. Soc., 1939, 1369.

31. Klemperer, F. W., Enzymatic oxidation of uric acid. J. Biol. Chem., 1945, 160, 111. 